\title{
Three-dimensional porous carbon nanotube sponges for high- performance anodes of microbial fuel cells
}

Celal Erbay ${ }^{\mathrm{a}, 1}$, Gang Yang ${ }^{\mathrm{b}, 1}$, Paul de Figueiredo ${ }^{\mathrm{c}, \mathrm{d}}$, Reza Sadr ${ }^{\mathrm{e}}$, Choongho $\mathrm{Yu}^{\mathrm{b} *}$, and Arum $\operatorname{Han}^{\mathrm{a}, \mathrm{f}_{* *}}$

${ }^{a}$ Department of Electrical and Computer Engineering, Texas A\&M University, College Station, Texas, 77843, USA

${ }^{b}$ Department of Mechanical Engineering, Texas A\&M University, College Station, Texas, 77843 , USA

${ }^{c}$ Department of Molecular Pathogenesis and Immunology, Texas A\&M Health Science Center, Bryan, Texas 77807, USA

${ }^{d}$ Department of Veterinary Pathobiology, Norman Borlaug Center, Texas A\&M University, College Station, Texas, 77843, USA

${ }^{e}$ Mechanical Engineering Program, Texas A\&M University at Qatar, Doha, Qatar

${ }^{f}$ Department of Biomedical Engineering, Texas A\&M University, College Station, Texas 77843, USA

Keywords: microbial fuel cell, carbon nanotube sponge, three dimensional electrodes, one-step synthesis

\section{Corresponding Authors}

* Choongho Yu, E-mail: chyu@tamu.edu Phone: +1-979-862-1073

** Arum Han, E-mail: arum.han@ece.tamu.edu Phone: +1-979-845-9686

${ }^{1}$ These authors equally contributed to this work. 


\begin{abstract}
Highly-porous, light-weight, and inexpensive three-dimensional (3D) sponges composed of interconnected carbon nanotubes (CNTs) without base materials synthesize with a facile and scalable one-step chemical vapor deposition process, and test as anode of microbial fuel cells (MFCs). The MFCs generates higher power densities of $2150 \mathrm{~W} \mathrm{~m}^{-3}$ (per anode volume) or 170 $\mathrm{W} \mathrm{m}^{-3}$ (per anode chamber volume), comparable to those of commercial 3D carbon felt electrodes test under the same conditions. The high performances attribute to excellent charge transfer between CNTs and microbes owing to 13 times lower charge transfer resistance compared to that of carbon felt. The material cost of producing these CNT sponge estimates to be $\sim \$ 0.1 / \mathrm{g}_{\mathrm{CNT}}$, significantly lower than that of other methods. In addition, the high production rate of about $3.6 \mathrm{~g} \mathrm{~h}^{-1}$ compared to typical production rate of $0.02 \mathrm{~g} \mathrm{~h}^{-1}$ of other CNT-based materials makes this process economically viable. The one-step synthesis method allowing selfassembly of 3D CNT sponges as they grow is low cost and scalable, making this a promising method for manufacturing high-performance anodes of MFCs, with broad applicability to microbial electrochemical systems in general.
\end{abstract}




\section{Introduction}

Microbial fuel cells (MFCs) generate clean power from wastewater by converting chemical energy into electrical energy [1]. This power is generated through catalytic activities of microorganisms that oxidize biodegradable organic substrate in wastewater, which release electrons and protons during that process that are then captured in the form of electricity [2]. However, low power production and high cost remains to be the major hurdles for MFCs to become economically viable [2]. One major part of such cost is the anode, where an ideal anode would be highly conductive to allow efficient electron transfer between electrically active bacteria $(\mathrm{EAB})$ and the anode, has larger surface area that allows EAB attachment throughout the anode, and be low cost [3]. The three-dimensional (3D) structure is of particular benefit in anodes. When a biofilm grows from a planar electrode, EABs close to the exposed surface of the electrode mainly participate in electron transfer. However as biofilm grows and becomes thick up to several tens of micrometers, electrons generated from the EAB are not properly transferred to the electrode due to low electrical conductivity of the biofilm. Therefore, it is necessary to alleviate these drawbacks while minimizing the cost of the anodes.

While most commonly used anode materials are carbon cloth, carbon felt, and carbon paper $[4,5]$, it has been found that 3D carbon brush structures can significantly increase power output by maximizing the contact of EABs to anode, and are now also broadly used [6]. In carbon brushes, straight long carbon fibers whose diameters are 7-10 micrometers are arranged in the radial direction that allows EABs to be attached throughout the brush electrode. This brush design is superior to 2D electrodes (eg. carbon cloth, carbon paper) because of the large surface area per volume. However the large spacing between the carbon fibers (typically in several tens 
to hundreds of micrometers) and relatively high ohmic resistance of this material leave further room for significant improvement.

Various nanomaterials have been explored to overcome such limitations, such as metal nanoparticles [7], graphene [5, 8-11], carbon nanotubes (CNTs) [12-18], and polymer composites with embedded nanoscale carbon materials [19-21], all providing orders of magnitude higher surface areas than that of 2D electrodes $\left(<1 \mathrm{~m}^{2} \mathrm{~g}^{-1}\right)$ and 3D brush electrodes $\left(\sim 0.7 \mathrm{~m}^{2} \mathrm{~g}^{-1}\right)$. However these nanomaterials generally require some sort of $2 \mathrm{D}$ or $3 \mathrm{D}$ support substrates such as carbon paper [16], carbon cloth [17], textile [13], and stainless steel mesh [18], which contains less conductive materials and/or limits thickness of nanomaterial layers to have 3D structures. Recent development in 3D nanostructures may alleviate such drawbacks. For instance, a graphene coated sponge [10] with stainless steel as a current collector, a graphene modified nickel foam [9], a graphene foam coated with polyaniline (PANI) [21] all have shown high performances by allowing efficient electron transfer and mass transport by combining highly conductive nanomaterials with 3D structures. Nonetheless, most of these highperformance $3 \mathrm{D}$ structured electrodes typically require complicated synthesis processes such as carbonization and reoxidation [8, 19]. This complexity significantly increases the cost of the electrodes as well as are difficult to scale-up, which makes these high performance electrodes impractical for most MFC applications.

Here, we synthesized porous and flexible 3D CNT sponges by using a simple and facile one-step process without the need for any substrates or base/sacrificial materials. One-step synthesis that does not require any pre and post processes to make the CNT sponges such as catalyst deposition on substrates or removal of unwanted materials was advantageous to fabricate them in a short time. The spontaneously formed sponge is also scalable, which makes it suitable 
for low-cost bulk manufacturing. The 3D CNT sponge anodes were tested in various MFC sizes to characterize their power density.

\section{Experimental}

\subsection{Preparation and characterization of CNT sponge electrode}

To synthesize the CNT sponge, a chemical vapor deposition (CVD) method was employed (Figure 1a). A three-zone furnace (Lindberg/Blue M STF55346C) equipped with a quartz tube ( 1 inch in diameter) was used to individually control the temperature of the reaction zones. Ferrocene (Sigma Aldrich, 98\%) and ethylene gas (Air gas, 99.999\%) were used as catalyst and carbon source, respectively. The quartz tube was first purged with argon gas (Air gas, $99.999 \%$ ) for 10 min under $400 \mathrm{sccm}$ followed by switching the gas to $\mathrm{H}_{2}$ (Air gas, $99.999 \%$ ) with $260 \mathrm{sccm}$. The furnace was then heated with programed temperature ramping rate. The reaction temperatures for zone 1 and zone 3 were set to $120^{\circ} \mathrm{C}$ and $650{ }^{\circ} \mathrm{C}$, respectively. The temperature ramping rate for zone 1 and zone 3 were set to $5{ }^{\circ} \mathrm{C} / \mathrm{min}$ and $65{ }^{\circ} \mathrm{C} / \mathrm{min}$, respectively. After zone 1 reached $120^{\circ} \mathrm{C}$, ethylene gas (Air gas, 99.999\%) of 80 sccm and argon gas of $80 \mathrm{sccm}$ were introduced to the furnace tube. After a 30-min growth reaction, a CNT sponge with $\sim 10 \mathrm{~cm}$ in length and $22 \mathrm{~mm}$ in diameter was formed (Figure 1b). The furnace was naturally cooled to room temperature under $200 \mathrm{sccm}$ Ar flow. Considering the low cost of raw materials, facile synthesis procedures, and high yields, this presented method is suitable for producing bulk-quantity sponge-like CNT structure

CNT sponge morphology was inspected by using a scanning electron microscope (SEM: Quanta 600, FEI) and a transmission electron microscope (TEM: JEM-2010, JEOL) before and after MFC operation. Raman data was obtained with a Raman confocal microscope (Jobin-Yvon LabRam, Horiba) with $632.8 \mathrm{~nm}$ excitation wavelength. 


\subsection{MFC setup and operation}

The synthesized CNT sponge as anode along with carbon felt (Morgan, UK) for comparison was tested in three different sizes of two-chamber MFCs (Fig. S1 and Fig. S2 for schematic illustration). Three different chamber sizes were used to fully characterize the CNT sponge anode performances at various size scales. Small (SMFC), medium (MMFC), and large MFC (LMFC) have two chambers (anode and cathode chambers) of 0.5, 20, and $120 \mathrm{~mL}$, respectively. The two chambers were separated by a proton exchange membrane (PEM) (Nafion $117^{\mathrm{TM}}$, Ion Power Inc.; $1 \mathrm{~cm}^{2}$ for SMFC; $7 \mathrm{~cm}^{2}$ for MMFC; $19.6 \mathrm{~cm}^{2}$ for LMFC) that was placed between silicon rubber gaskets to prevent liquid leak. CNT sponge anodes $\left(1 \times 1 \times 0.3 \mathrm{~cm}^{3}\right.$; same for all MFCs) and carbon cloth cathodes $\left(1 \times 1 \mathrm{~cm}^{2}\right.$ for SMFC; $2 \times 2 \mathrm{~cm}^{2}$ for MMFC; $3 \times 4 \mathrm{~cm}^{2}$ for LMFC) having platinum catalysts on one side (10 wt $\% \mathrm{Pt} / \mathrm{C}, 0.5 \mathrm{mg}$ of $\mathrm{Pt}$ per $\mathrm{cm}^{2}$, ElectroChem, Inc.) were used. Titanium wires were used to hook the electrodes for electrical connection.

The anode chambers were inoculated with anaerobically activated sludge (Austin Wastewater Plant). The anode chambers were fed with a medium containing sodium acetate (1.5 $\mathrm{g} \mathrm{L}^{-1}$ ) and autoclaved anaerobic nutrient mineral buffer (NMB, $\mathrm{pH}$ 7.0) solution [22]. The MFCs were operated in a batch mode and acetate was inoculated after the voltage dropped below 50 $\mathrm{mV}$. Nitrogen was purged for $15 \mathrm{~min}$ to make the chambers anaerobic after each inoculation. The medium was mixed by using a magnetic stirrer at $350 \mathrm{rpm}$ during the experiment (only for the MMFC and LMFC due to the size limitation). The cathode chambers were filled with $100 \mathrm{mM}$ ferricyanide $\left(\left[\mathrm{Fe}(\mathrm{CN})_{6}\right]^{3-}\right)$.

Cell voltage across a load resistor $(1 \mathrm{k} \Omega)$ was recorded every $120 \mathrm{sec}$ using a multiplexer

(NI PXI-2575, National Instruments) for continuous voltage measurements via a LabView ${ }^{\mathrm{TM}}$ (National Instruments) interface [23]. Polarization curves were obtained by varying the load 
resistor from $10 \mathrm{k} \Omega$ to $100 \Omega$ when voltage was stable after several operation cycles. Power $(P)$

was calculated by $P=V^{2} R^{-1}$ based on the recorded voltage $(V)$ and load resistance $(R)$. The current and power densities were normalized by the volume of anode $(0.3 \mathrm{~mL})$ or anode chambers $(0.5,20,120 \mathrm{~mL})$ for each case.

\subsection{Electrochemical Impedance Spectroscopy (EIS) Measurement}

EIS data was obtained with an electrochemical workstation (604D, CHI) with the MMFC setup to test both the CNT sponge and carbon felt at the open circuit voltage (OCV) in the frequency range of $0.01 \mathrm{~Hz}$ to $100 \mathrm{kHz}$ with an ac signal of $5 \mathrm{mV}$ amplitude after the MMFC was operated for $\sim 50$ days. The impedance data was measured in a two-electrode mode, using the CNT sponge anode as the working electrode and the Pt cathode as both the counter and reference electrodes.

\subsection{Biofilm Characterization}

To inspect the biofilms on the CNT sponge and carbon felt, the anode was first rinsed with phosphate buffered saline (PBS), and then microbes were fixed using 4\% glutaraldehyde and $4 \%$ formaldehyde for 5 hours. The samples were carefully rinsed three times in PBS (pH 7.0) and then once in deionized water, followed by a series of dehydration steps using increasing concentrations of ethanol $(25,50,75$, and $95 \mathrm{wt} \% ; 10 \mathrm{~min}$ for each stage with very gentle periodic agitation) and then thorough drying at room temperature overnight. The samples were coated with $\sim 5$-nm thick $\mathrm{Pt} / \mathrm{Pd}$ for inspection under the SEM.

\section{Results}

\subsection{Fabrication and characterization of CNT sponge}


As-synthesized CNT sponge (Figure 1c) shows highly porous structure ( $98 \%$ porosity), and is comprised of randomly oriented and entangled CNTs. The structural integrity is partially resulting from the entanglement of the CNTs, which is key in allowing the 3D free-standing feature. The entangled and porous structures rather than densely-packed clumped ones are ideal for microbes to penetrate and grow from the exposed surfaces of the CNTs. The percolated CNT networks also provide excellent pathways for electrons to travel through. Further TEM inspection (Figure 1d) displays the graphitic layers of the CNT, suggesting excellent electron transport through the CNT. In Raman spectra (Figure 1e), the intensity ratio of D-band (1330 $\mathrm{cm}^{-}$

$\left.{ }^{1}\right)$ to G-band $\left(1580 \mathrm{~cm}^{-1}\right)$, which is commonly used as a qualitative number to show the defect density in the graphitic structure, was found to be $\mathrm{I}_{\mathrm{D}} / \mathrm{I}_{\mathrm{G}}=0.54$. This suggests that the presented CNT sponge has a relatively high density of defects like dangling bond, which makes the CNT surfaces more reactive. As seen in Figure 1d, the outer graphitic layers are more or less discontinuous, but aligned straight lines indicating stacked graphitic layers were observed for the inner part of the CNT. This implies that the inner walls are still excellent electron conductors while the outer walls are adequate to interact with microbes due to the relatively high surface energy. $\pi-\pi$ interactions between the graphitic layers and microbial nanowires are expected to make the attachment of microbes on the CNTs even more favorable [3, 18, 24].

\subsection{CNT sponge as the anode in MFC}

We first tested the CNT anode in SMFC. The voltage increased to $\sim 250 \mathrm{mV}$ over a $1 \mathrm{k} \Omega$ load resistor in about one day, as shown in Figure 2a. Meanwhile carbon felt anode produced a slightly lower voltage of $170 \mathrm{mV}$. The volumetric maximum power density (normalized to the anode chamber volume of the SMFC) generated by the CNT sponge anode was $\sim 170 \mathrm{~W} \mathrm{~m}^{-3}$, 
which was approximately 1.4 times higher than that of a commercial carbon felt $\left(\sim 120 \mathrm{~W} \mathrm{~m}^{-3}\right)$, as shown in Figure 2b. Here the CNT sponge and carbon felt electrodes filled approximately $60 \%$ of the anode chambers.

In order to evaluate the long-term performance of the CNT sponge anode, MMFC whose anode chamber volume is 40 -times larger $(20 \mathrm{~mL})$ was used since the SMFC required frequent media replenishment. After 5 days from inoculation with wastewater, voltage over a $1 \mathrm{k} \Omega$ load resistor reached a higher voltage of $\sim 550 \mathrm{mV}$ (Figure 3a), which was maintained for more than 50 days, indicating its high stability. The maximum volumetric power density (normalized to the anode chamber volume) of the MMFC with the CNT sponge anode $\left(14.1 \mathrm{~W} \mathrm{~m}^{-3}\right)$ was 1.3 times higher than that of the MMFC with carbon felt $\left(10.8 \mathrm{~W} \mathrm{~m}^{-3}\right)$, as shown in Figure $3 \mathrm{~b}$. The percentage improvement was similar to that obtained when using the SMFC. This long-term test result shows that porous $3 \mathrm{D}$ CNT sponge anode developed here has better performance compared to commercial carbon felt frequently used as 3D anode materials in MFCs.

This improved performance could be attributed to more uniform biofilm growth on the CNT sponge compared to that of the carbon felt, based on the SEM images after 50 days of operation (Figure 3c,d for the CNT sponge anode; Figure 3e,f for the carbon felt). CNTs were not observed in the CNT sponge anode, suggesting that microbes completely and uniformly covered the entire surface of the CNT sponge anode. On the contrary, microbes on the carbon felt were mainly attached to the carbon fibers, resulting in non-uniform and less dense biofilm. This difference suggests a substantially improved contact between the anode and the biofilm in the case of CNT sponge, which can be due to high surface area of the CNT sponge as well as the $\pi-\pi$ interactions between the graphitic layers of the CNTs and the attached microbes. 


\subsection{Electrochemical impedance spectroscopy analysis}

In addition to attachment and growth of EABs to the $3 \mathrm{D}$ anode structure, it is also important to have effective charge transfer from the EABs in the biofilm to the electrode. Such electron transfer can be indicated by the charge transfer resistances measured using electrochemical impedance spectroscopy (EIS). EIS were carried out with both the CNT sponge and carbon felt anodes used in the MMFCs after 50 days of operation. The Nyquist plot in Figure 4 displays both semicircle in the high frequency region and sloping line in the low frequency region for both the CNT sponge and the carbon felt. The lowest real part indicating the ohmic resistance [25] were similar (5 $\Omega$ ) since electrolyte solutions and MFC configurations for both cases were identical. On the other hand, the diameters of the semicircle indicating the charge transfer resistance $[26,27]$ were measured to be $4 \Omega$ and $52 \Omega$, respectively for the CNT sponge and the carbon felt. This suggests a much superior charge transfer characteristics between the CNT sponge and the biofilm. From the SEM images in Fig. 3, the biofilm on the CNT sponge can be seen as thick, continuous, and uniform, while those on the carbon felt were thin and concentrated near the fibers of the felt, which qualitatively explains why the charge transfer is more effective in the case of our sponge compared to that of carbon felt. This effective charge transfer can be attributed to the large surface area of the CNT sponge and the improved interaction between the CNT sponge and the microbes via $\pi$ - $\pi$ interactions [18].

\section{Discussion}

The CNT sponge anode was also tested in the LMFC having 6 times larger anode volume compared to the MMFC. The power densities of the CNT sponge anodes in the SMFC, MMFC, and LMFC cases were compared by normalizing against the sponge anode volume (Figure 5a) 
and the anode chamber volume (Figure 5b). Both normalization methods were used to be able to compare to literature, as some report power densities based on the anode chamber volume and some based on the anode volume. It should be noted that the volume of the CNT sponge anode is identical for all experiments in this study. With larger chamber volumes, the power density per volume of the CNT sponge anode was highest, reaching $2150 \mathrm{~W} \mathrm{~m}^{-3}$ for LMFC, which is 2.3 and 7.6 times higher than those of the MMFC $\left(943 \mathrm{~W} \mathrm{~m}^{-3}\right)$ and of the SMFC $\left(283 \mathrm{~W} \mathrm{~m}^{-3}\right)$ (Figure 5a). This increment can be ascribed to more microbes in the larger MFC chamber, suggesting that active surface area of the CNT sponge is sufficiently large as to not saturate the power generation. On the other hand, the power density normalized to the anode chamber volume was highest (170 $\mathrm{W} \mathrm{m}^{-3}$ ) from the SMFC (Figure $5 \mathrm{~b}$ ), which has a significantly higher volume percentage $(60 \%)$ of anode chamber occupied by the anode, compared to the cases of MMFC (1.5\%) and LMFC $(0.25 \%)$. These results suggest that it is better to have a large chamber volume to obtain high power generation, at the same time filling a significant portion of the chamber volume with anode will be ideal to effectively utilize the total volume of the cell. We also expect that further study with single-chamber air-cathode MFCs may improve the maximum power density of twochamber MFCs in this work, which we plan to do as a follow-up study.

As shown in Table 1, reported power densities in literature greatly vary not only depending on the MFC configurations (e.g., the number of chambers, the size of electrodes and PEM) and operating conditions (e.g., microorganisms and substrates used), but also depending on the size/volume of electrodes used to calculate the power densities and the volume ratio of the chamber to electrode. Table 1 compares the power density of our CNT sponge anode with previously reported nanomaterial based 3D anodes in MFCs. Among these representative results, our LMFC and SMFC was the best in terms of the power density per anode volume and per 
anode chamber volume, respectively. For example, when anodes were made of insulating polyurethane sponges decorated with commercially available CNTs [15] or graphene [10] by a dipping method, their power density per chamber volume was, respectively, measured to be only $0.66 \mathrm{~W} \mathrm{~m}^{-3}$ and $1.05 \mathrm{~W} \mathrm{~m}^{-3}$, significantly lower than our values presumably due to poor electrical contact between the nanomaterials due to the insulating surfactants and/or binders. Test using the 3D graphene sponge anode tested in a two-chamber MFC [8] resulted in a volumetric power density (per chamber volume) of $3.41 \mathrm{~W} \mathrm{~m}^{-3}$, showing only $8 \%$ increase compared to that of carbon felt anode, potentially due to the small pore sizes in the graphene sponge anode.

Overall, most importantly, the synthesis process for the CNT sponges presented here is scalable, simple, facile, and inexpensive, compared to those in literature. For instance, longer and complicated processes such as polymerization and carbonization were necessary to obtain $3 \mathrm{D}$ nitrogen-enriched carbon nanoparticle coated anode that resulted from the carbonization of PANI and natural fibrous loofah sponge [19]. Graphene oxide anode required very long ( $>2$ days) processes with expensive nickel foams as substrates [9]. Our one-step processing method has a very low production cost about $\sim \$ 0.1 / \mathrm{g}_{\mathrm{CNT}}$ or $\sim \$ 4.7 / \mathrm{L}$, whose density is $\sim 47 \mathrm{mg} / \mathrm{cm}^{3}$, which is much lower than those of previously reported methods [28-33]. The calculated cost here is based on using $0.3 \mathrm{~g}$ of ferrocene $(\$ 108 / 500 \mathrm{~g}), 2.4 \mathrm{~L}$ of $\mathrm{C}_{2} \mathrm{H}_{4}\left(\$ 22 \mathrm{for} / 300 \mathrm{ft}^{3}\right), 7.8 \mathrm{~L}$ of $\mathrm{H}_{2}(\$ 45$ for $\left.300 \mathrm{ft}^{3}\right)$, and $2.4 \mathrm{~L}$ of $\mathrm{Ar}\left(\$ 48\right.$ for $\left.300 \mathrm{ft}^{3}\right)$ for the 30 min synthesis time. The total cost was then normalized to the current production rate of $\sim 3.6 \mathrm{~g} / \mathrm{h}$. This production rate was also orders of magnitude higher $(\sim 3.6 \mathrm{~g} / \mathrm{h}$, representing $20 \mathrm{~cm} / \mathrm{h}$ of a $2.2 \mathrm{~cm}$ diameter CNT sponge) compared to other nanomaterial-based anode synthesis $(\sim 0.02 \mathrm{~g} / \mathrm{h})[28,29,31,32]$. The process is also scalable, where the diameter of the CNT sponge is controlled by the diameter of the furnace tube used and the length is controlled by the synthesis time (currently $1 \mathrm{~h}$ to obtain a $20 \mathrm{~cm}$ long and 2 
$\mathrm{cm}$ diameter CNT sponge). Thus simply using a larger-diameter furnace tube and longer synthesis time can easily result in scaled-up production of the presented 3D CNT sponge electrode materials. Here, the presented CNT sponge anode shows not only high power density in MFC applications, but also low cost and scalability, which will have broad applicability in microbial electrochemical cell systems (e.g., MFC, microbial electrolysis cells, and microbial desalination cells) in general.

\section{Conclusion}

We fabricated a 3D sponge-like anode consisting of self-assembled, interconnected CNTs by using facile and inexpensive one-step CVD method without substrates. The highly porous, flexible, and light-weight sponge anode generated higher power densities of $2150 \mathrm{~W} \mathrm{~m}^{-3}$ per anode volume and $170 \mathrm{~W} \mathrm{~m}^{-3}$ per anode chamber volume, compared to those in literature. These power densities were also higher than those of commercial carbon felt electrode tested with the same configuration. This improved performance can be attributed to enhanced charge transfer between the CNT sponge anode and microbial biofilm based on the EIS results, in addition to large surface areas and favorable $\pi-\pi$ interactions between microbial nanowires and CNTs. The low cost simple to fabricate 3D CNT sponge anode presented here provides a new concept for designing MFC anodes as well as promising approach to generate electricity from wastewater in large scale applications at economically viable cost. 


\section{Supporting Information}

Supplementary data associated with this article can be found in the online version Acknowledgements

This work was supported by the Qatar National Research Foundation (QNRF) grant \#NPRP 5671-2-278 and QNRF grant \#NPRP 7-1634-2-604. G.Y. and C.Y. also acknowledge financial supports from the US National Science Foundation (CMMI \#1030958). C.E. is supported by the Ministry of National Education of the Republic of Turkey. 


\section{References}

[1] B.E. Logan, B. Hamelers, R. Rozendal, U. Schröder, J. Keller, S. Freguia, P. Aelterman, W. Verstraete, K. Rabaey, Environ Sci Technol., 40 (2006) 5181-5192.

[2] B.E. Logan, K. Rabaey, Science, 337 (2012) 686-690.

[3] G. Reguera, K.D. McCarthy, T. Mehta, J.S. Nicoll, M.T. Tuominen, D.R. Lovley, Nature, 435 (2005) 1098-1101.

[4] M. Zhou, M. Chi, J. Luo, H. He, T. Jin, J Power Sources, 196 (2011) 4427-4435.

[5] Y. Zhang, G. Mo, X. Li, W. Zhang, J. Zhang, J. Ye, X. Huang, C. Yu, J Power Sources, 196 (2011) 5402-5407.

[6] A.J. Hutchinson, J.C. Tokash, B.E. Logan, J Power Sources, 196 (2011) 9213-9219.

[7] Y. Fan, S. Xu, R. Schaller, J. Jiao, F. Chaplen, H. Liu, Biosens Bioelectron., 26 (2011) 19081912.

[8] W. Chen, Y.-X. Huang, D.-B. Li, H.-Q. Yu, L. Yan, RSC Adv, 4 (2014) 21619-21624.

[9] H. Wang, G. Wang, Y. Ling, F. Qian, Y. Song, X. Lu, S. Chen, Y. Tong, Y. Li, Nanoscale, 5 (2013) 10283-10290.

[10] X. Xie, G. Yu, N. Liu, Z. Bao, C.S. Criddle, Y. Cui, Energy Environ Sci, 5 (2012) 68626866.

[11] V. Gadhamshetty, N. Koratkar, Nano Energy, 1 (2012) 3-5.

[12] J.E. Mink, J.P. Rojas, B.E. Logan, M.M. Hussain, Nano Lett., 12 (2012) 791-795.

[13] X. Xie, L. Hu, M. Pasta, G.F. Wells, D. Kong, C.S. Criddle, Y. Cui, Nano Lett., 11 (2011) 291-296.

[14] H. Ren, S. Pyo, J.-I. Lee, T.-J. Park, F.S. Gittleson, F.C.C. Leung, J. Kim, A.D. Taylor, H.S. Lee, J. Chae, J Power Sources, 273 (2015) 823-830. 
[15] X. Xie, M. Ye, L. Hu, N. Liu, J.R. McDonough, W. Chen, H.N. Alshareef, C.S. Criddle, Y. Cui, Energy Environ Sci, 5 (2012) 5265-5270.

[16] H.-Y. Tsai, C.-C. Wu, C.-Y. Lee, E.P. Shih, J Power Sources, 194 (2009) 199-205.

[17] T. Sharma, A.L. Mohana Reddy, T.S. Chandra, S. Ramaprabhu, Int J Hydrogen Energ, 33 (2008) 6749-6754.

[18] C. Erbay, X. Pu, W. Choi, M.-J. Choi, Y. Ryu, H. Hou, F. Lin, P. de Figueiredo, C. Yu, A. Han, J Power Sources, 280 (2015) 347-354.

[19] Y. Yuan, S. Zhou, Y. Liu, J. Tang, Environ Sci Technol., 47 (2013) 14525-14532.

[20] Y. Zhao, K. Watanabe, K. Hashimoto, Phys. Chem. Chem. Phys., 13 (2011) 15016-15021.

[21] Y.C. Yong, X.C. Dong, M.B. Chan-Park, H. Song, P. Chen, ACS nano, 6 (2012) 23942400.

[22] C. Erbay, S. Carreon-Bautista, E. Sanchez-Sinencio, A. Han, Environ Sci Technol., 48 (2014) 13992-13999.

[23] H. Hou, L. Li, C.U. Ceylan, A. Haynes, J. Cope, H.H. Wilkinson, C. Erbay, P.d. Figueiredo, A. Han, Lab Chip, 12 (2012) 4151-4159.

[24] N.S. Malvankar, D.R. Lovley, ChemSusChem, 5 (2012) 1039-1046.

[25] X. Pu, G. Yang, C. Yu, J Electrochem Soc, 162 (2015) A1396-A1400.

[26] Y. Qiao, S.J. Bao, C.M. Li, X.Q. Cui, Z.S. Lu, J. Guo, ACS nano, 2 (2008) 113-119.

[27] X. Pu, C. Yu, Nanoscale, 4 (2012) 6743-6747.

[28] X.C. Gui, J.Q. Wei, K.L. Wang, A.Y. Cao, H.W. Zhu, Y. Jia, Q.K. Shu, D.H. Wu, Adv Mater, 22 (2010) 617-621.

[29] H. Wang, Z. Wu, A. Plaseied, P. Jenkins, L. Simpson, C. Engtrakul, Z. Ren, J Power Sources, 196 (2011) 7465-7469. 
[30] X.C. Gui, Z.P. Zeng, Y. Zhu, H.B. Li, Z.Q. Lin, Q.M. Gan, R. Xiang, A.Y. Cao, Z.K. Tang, Adv Mater, 26 (2014) 1248-1253.

[31] Z.P. Zeng, X.C. Gui, Z.Q. Lin, L.H. Zhang, Y. Jia, A.Y. Cao, Y. Zhu, R. Xiang, T.Z. Wu, Z.K. Tang, Adv Mater, 25 (2013) 1185-1191.

[32] Q.Y. Peng, Y.B. Li, X.D. He, X.C. Gui, Y.Y. Shang, C.H. Wang, C. Wang, W.Q. Zhao, S.Y. Du, E.Z. Shi, P.X. Li, D.H. Wu, A.Y. Cao, Adv Mater, 26 (2014) 3241-3247.

[33] X. Pu, G. Yang, C. Yu, Adv Mater, 26 (2014) 7456-7461. 
Table 1

\begin{tabular}{|c|c|c|c|c|c|c|}
\hline $\begin{array}{c}\text { Anode } \\
(\mathrm{mL})\end{array}$ & $\begin{array}{c}\text { Anode } \\
\text { chamber } \\
(\mathrm{mL})\end{array}$ & $\begin{array}{l}\text { Cathode } \\
\left(\text { area } \mathbf{c m}^{2}\right)\end{array}$ & $\begin{array}{l}\text { Inoculum and media } \\
\text { (MFC type, catholyte) }\end{array}$ & $\begin{array}{c}\text { Power density per } \\
\text { anode volume } \\
\left(\mathrm{W} / \mathbf{m}^{3}\right)\end{array}$ & $\begin{array}{c}\text { Power density per } \\
\text { anode chamber } \\
\text { volume }\left(\mathrm{W} / \mathbf{m}^{3}\right) \\
\end{array}$ & Ref. \\
\hline $\begin{array}{c}\text { Graphene-sponge SSM } \\
\text { as electron collector } \\
(0.4)\end{array}$ & 150 & $\begin{array}{l}\text { Pt-CC } \\
(10)\end{array}$ & $\begin{array}{c}\text { Wastewater with glucose } \\
\text { (H-type, air) }\end{array}$ & 394 & $1.05^{*}$ & [10] \\
\hline $\begin{array}{c}\text { CNT coated sponge } \\
(0.2)\end{array}$ & 150 & $\begin{array}{l}\text { CNT-sponge Pt } \\
\text { (1) }\end{array}$ & $\begin{array}{l}\text { Wastewater with glucose } \\
\text { (H-type, air) }\end{array}$ & $990 *$ & 0.66 & [15] \\
\hline $\begin{array}{c}\text { CNT coated sponge } \\
(0.2)\end{array}$ & 0.2 & $\begin{array}{c}\text { CNT-sponge Pt } \\
\text { (1) }\end{array}$ & $\begin{array}{l}\text { Wastewater with glucose } \\
\text { (two chapber, O2 } \\
\text { saturated PBS) }\end{array}$ & $325^{*}$ & 325 & [15] \\
\hline $\begin{array}{c}\text { Graphene-sponge } \\
(0.8)\end{array}$ & 100 & $\begin{array}{l}\text { Carbon paper } \\
\text { (9) }\end{array}$ & $\begin{array}{l}\text { Mix culture acetate } \\
\text { (two chambers, } \\
\text { ferricyanide) }\end{array}$ & 427 & $3.41 *$ & [8] \\
\hline $\begin{array}{l}\mathrm{N} \text {-enriched carbon } \\
\text { nanoparticle modified } \\
\text { loofah sponge (1.5) }\end{array}$ & 28 & $\mathrm{Pt}-\mathrm{CC}(7)$ & $\begin{array}{l}\text { Activated sludge } \\
\text { (single chamber -air } \\
\text { cathode) }\end{array}$ & $509 *$ & $27.2 *$ & [19] \\
\hline $\begin{array}{l}\text { Reduced Graphene } \\
\text { Oxide Nickel Foam } \\
\text { (1) }\end{array}$ & 25 & $\mathrm{CC}(70)$ & $\begin{array}{l}\text { SO-MR1 with TSB (two } \\
\text { chambers, ferricyanide) }\end{array}$ & 661 & 27 & [9] \\
\hline $\begin{array}{l}\text { CNT sponge } \\
\quad(0.3)\end{array}$ & 0.5 & Pt-CC (1) & $\begin{array}{l}\text { Wastewater with acetate } \\
\text { (two chambers } \\
\text { ferricyanide) }\end{array}$ & 283 & 170 & $\begin{array}{l}\text { This } \\
\text { work }\end{array}$ \\
\hline $\begin{array}{l}\text { CNT sponge } \\
\quad(0.3)\end{array}$ & 20 & $\mathrm{Pt}-\mathrm{CC}$ (4) & $\begin{array}{l}\text { Wastewater with acetate } \\
\text { (two chambers } \\
\text { ferricyanide) }\end{array}$ & 943 & 14.1 & $\begin{array}{l}\text { This } \\
\text { work }\end{array}$ \\
\hline $\begin{array}{l}\text { CNT sponge } \\
\quad(0.3)\end{array}$ & 120 & Pt-CC (4) & $\begin{array}{c}\text { Wastewater with acetate } \\
\text { (two chambers } \\
\text { ferricyanide) }\end{array}$ & 2150 & 5.3 & $\begin{array}{l}\text { This } \\
\text { work }\end{array}$ \\
\hline
\end{tabular}

*Calculated values based on the reported data. 
Figure 1
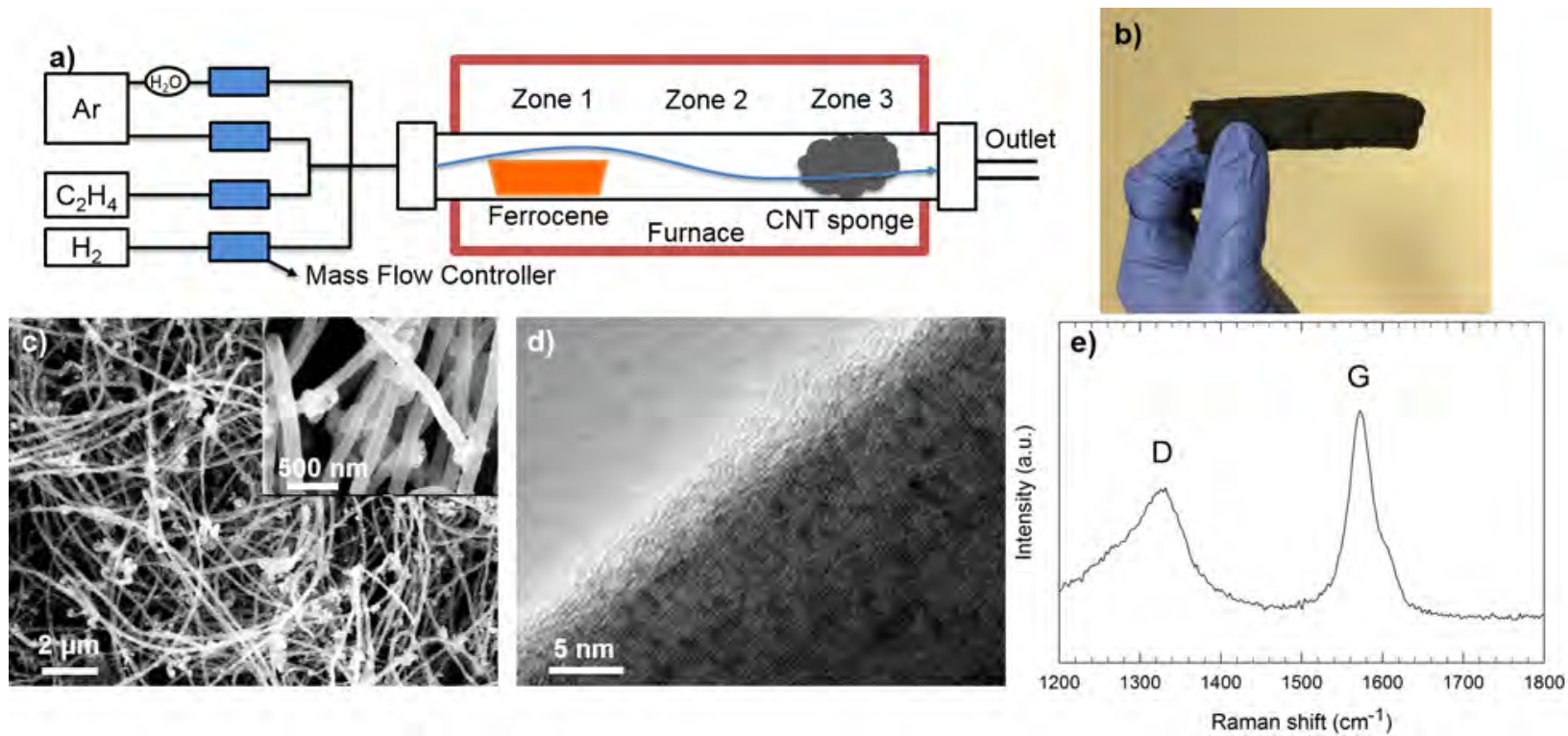
Figure 2

a)
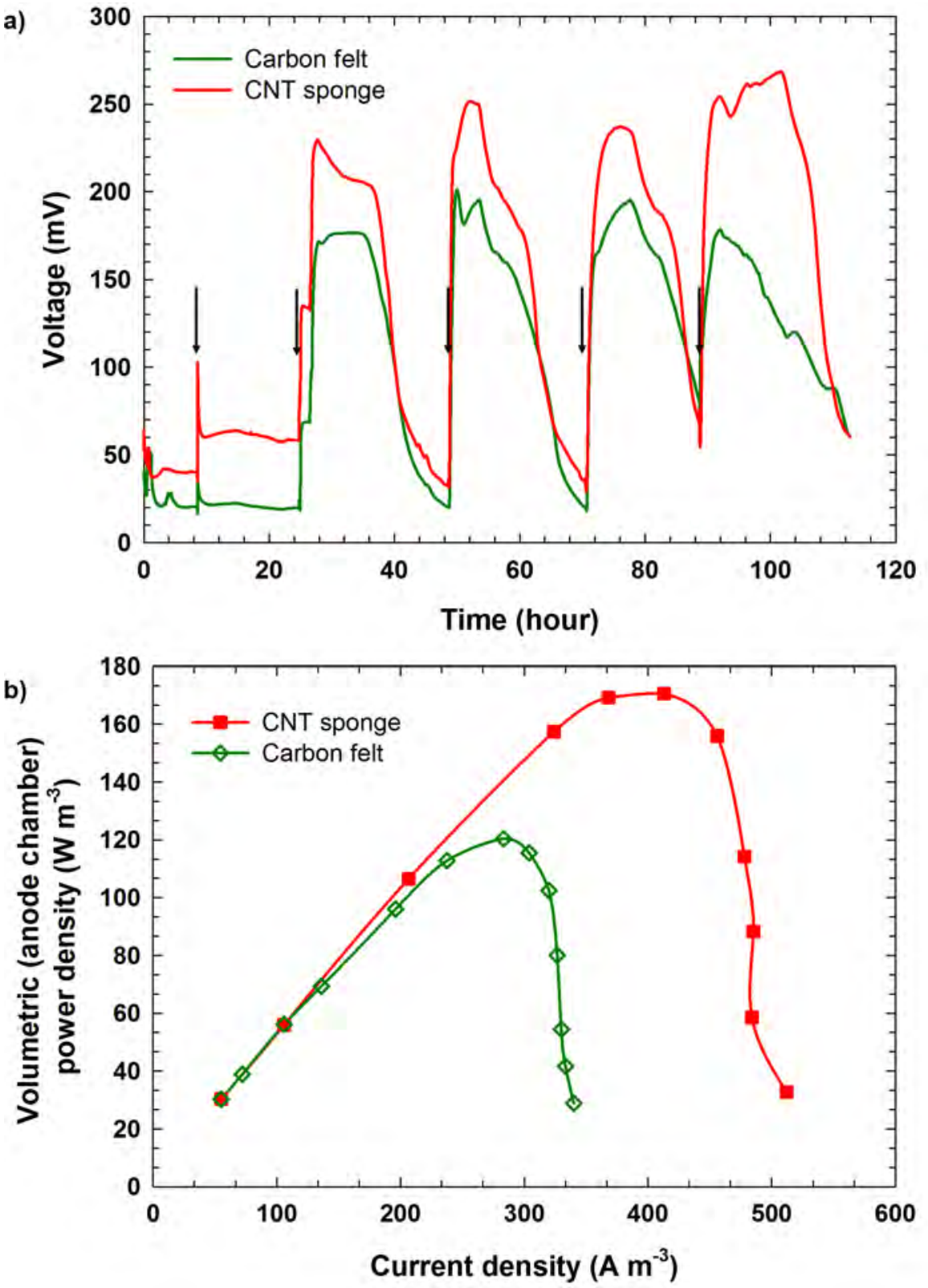
Figure 3
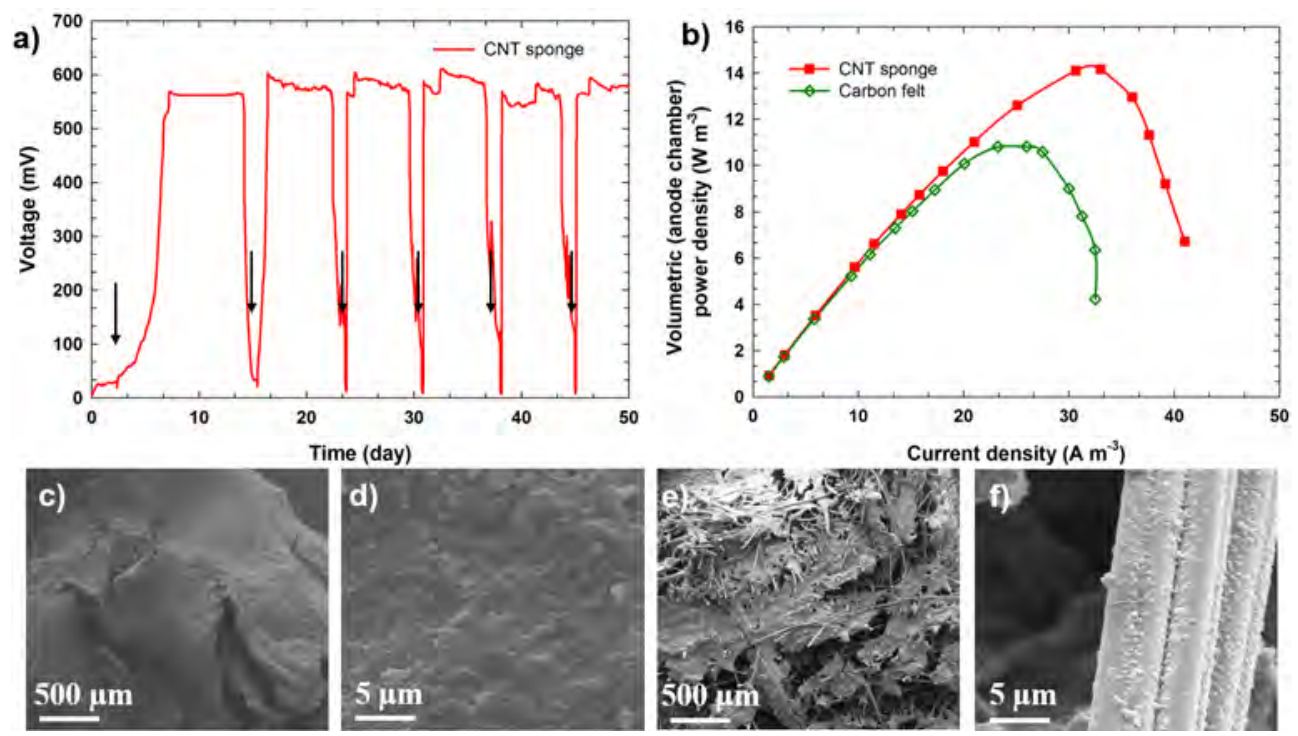
Figure 4

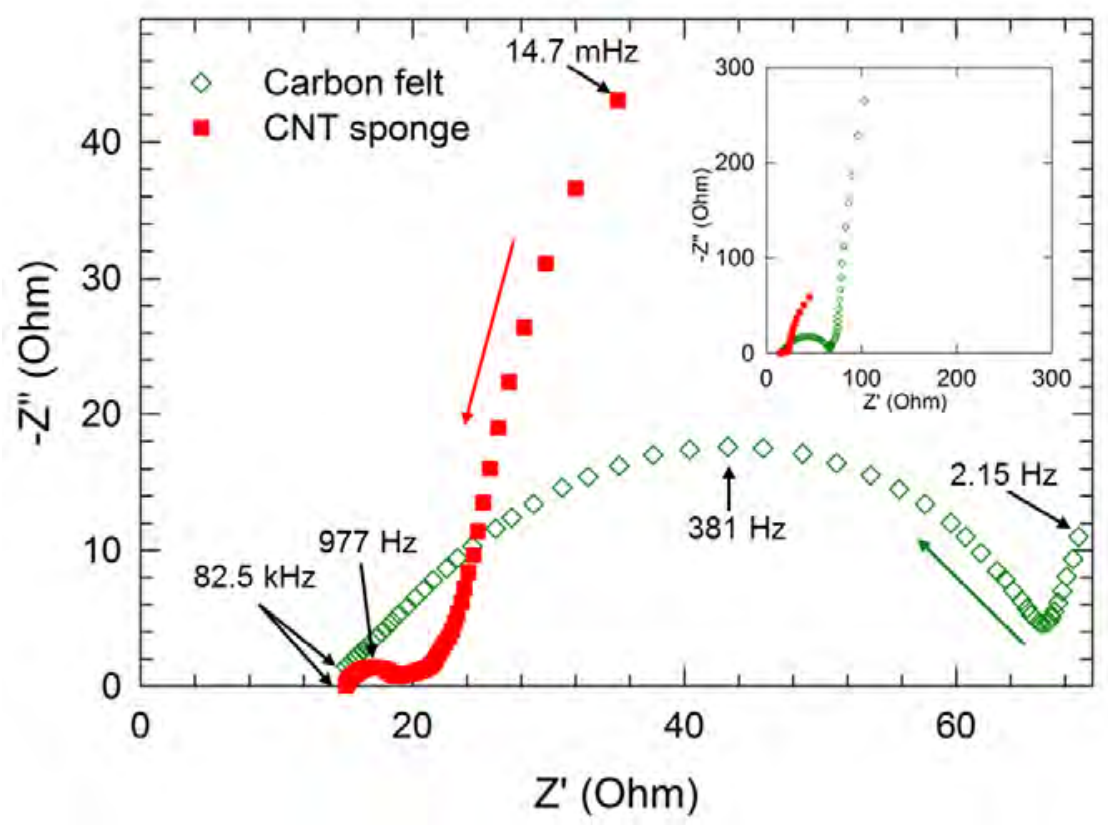


Figure 5
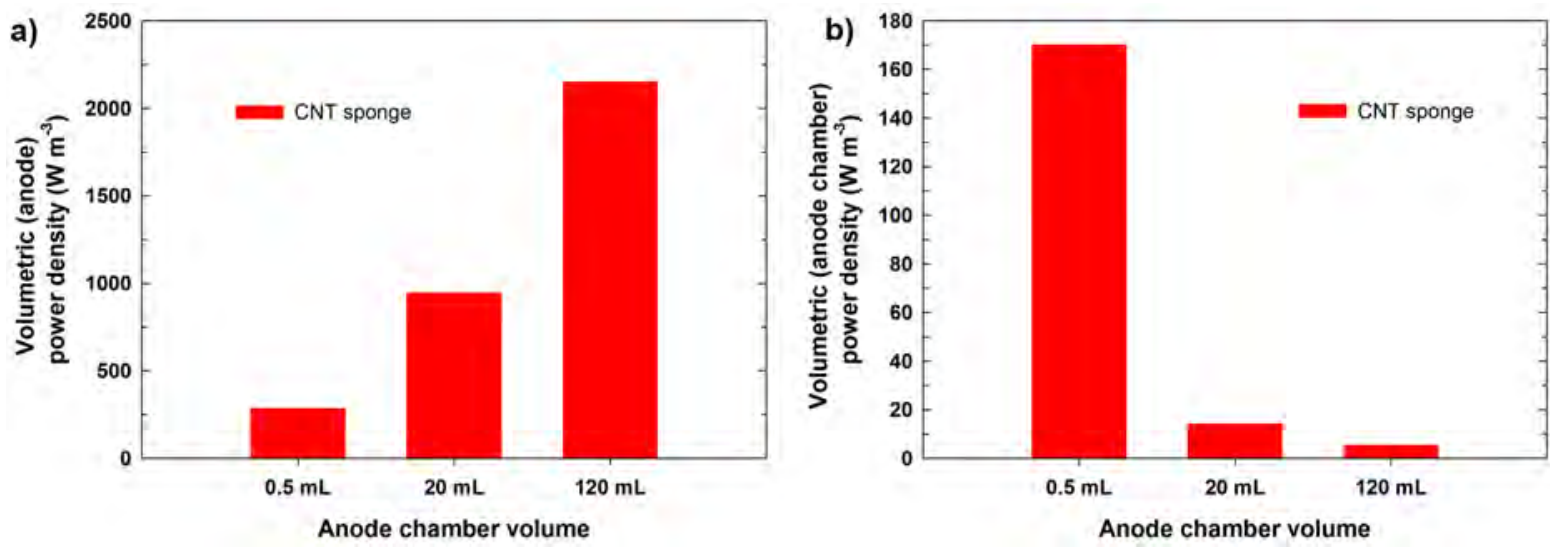